\title{
Estudo de argilas usadas em cerâmica vermelha
}

\author{
(Study of clays used in red ceramic)
}

\author{
R. S. Macedo, R. R. Menezes, G. A. Neves, H.C. Ferreira \\ Departamento de Engenharia de Materiais, Universidade Federal de Campina Grande \\ Av. Aprígio Veloso 882, Bodocongó, Campina Grande, PB 58109-970 \\ reginaldo@dema.ufcg.edu.br,heber@dema.ufcg.edu.br
}

\begin{abstract}
Resumo
Este trabalho tem por objetivo a caracterização física e mineralógica de argilas utilizadas industrialmente para a produção de blocos cerâmicos. As argilas foram caracterizadas por meio da determinação de distribuição granulométrica, limites de Atterberg e composição química, difração de raios X, e análise térmica diferencial e gravimétrica. Foram conformados corpos de prova por extrusão. Os corpos foram queimados a 800,900 e $1000{ }^{\circ} \mathrm{C}$ e em seguida determinou-se absorção de água e módulo de ruptura à flexão. Também foram determinadas a absorção de água e a resistência à compressão simples de blocos cerâmicos comerciais produzidos com as amostras analisadas. Pode-se observar que as amostras apresentam limites de plasticidade dentro da faixa indicada para cerâmica vermelha e que são constituídas basicamente por caulinita, quartzo, mica e feldspatos, com algumas amostras apresentando goetita e hidróxido sílico-aluminoso. Concluiu-se também que a caracterização permite estimar as argilas adequadas ou não para a produção de blocos cerâmicos.
\end{abstract}

Palavras-chave: argilas, blocos cerâmicos, cerâmica vermelha, caracterização.

\begin{abstract}
The aim of this work was to characterize clays industrially used for the production of ceramic bricks. The clays were characterized by particle size distribution, Atterberg limits and chemical composition determination, $X$-ray diffraction and differential thermal and gravimetric analyses. Test specimens were prepared by extrusion and fired at 800,900 and $1000{ }^{\circ} \mathrm{C}$. Fired test specimens were characterized in terms of water absorption and mechanical strength. Commercially produced ceramic bricks were also characterized in terms of water absorption and mechanical strength. The results showed that clays had plasticity limits in the range indicated for brick clay industry and are composed by kaolinite, quartz, mica and feldspars, with some samples presenting goethite and silicon-aluminous hydroxide. The suitability to produce ceramic bricks using the studied samples could be determined by the characterization process.
\end{abstract}

Keywords: clays, ceramic bricks, red ceramic, characterization.

\section{INTRODUÇ̃̃OO}

A indústria cerâmica brasileira tem participação de cerca de $1 \%$ no PIB nacional, sendo aproximadamente $40 \%$ desta participação representada pelo setor de cerâmica vermelha. O setor de cerâmica vermelha consume cerca de 70 milhões de toneladas de matérias-primas por ano, através das $12 \mathrm{mil}$ empresas distribuídas pelo país, a maioria de pequeno porte, gerando centenas de milhares de empregos $[1,2]$.

Apesar da grande importância econômica e social da cerâmica vermelha no país, a grande maioria dos jazimentos de argilas não é devidamente estudada, não havendo, em geral, dados técnico-científicos que orientem sua aplicação industrial da maneira mais racional e otimizada possível [3].

O Estado da Paraíba possui uma grande quantidade de indústrias de cerâmica vermelha com uma grande produção de blocos e telhas. Entretanto, o Estado não foge à regra do restante do país, não havendo o conhecimento adequado e necessário acerca das características tecnológicas das argilas utilizadas por essa indústria, apesar dos esforços [3-6] que vêm sendo desenvolvidos nos últimos anos visando suprir essa lacuna tecnológica do setor cerâmico paraibano.

Em geral, as argilas são materiais muito heterogêneos, cujas características dependem da sua formação geológica e da localização da extração. No Estado da Paraíba a maior parte das argilas é procedente das várzeas dos rios e açudes; entretanto, o estado apresenta 17 bacias hidrográficas, cada uma com características e particularidades geológicas, o que propicia uma grande complexidade e variabilidade composicional às argilas extraídas e utilizadas industrialmente.

Para a utilização das argilas em processos industriais é importante e indispensável uma identificação completa do tipo de argila e de suas propriedades, para estabelecer quais as formulações e condições de processamento são mais adequadas para se obter produtos com as propriedades finais desejadas [7]. As propriedades do produto final estão estreitamente relacionadas às características iniciais 
das matérias-primas, como granulometria, plasticidade e composição mineralógica [7-8], dentre outras.

Em vários paises o entendimento das características físicas, químicas e mecânicas dos materiais argilosos já é considerado uma das etapas mais importantes do processamento, fundamental para se obter produtos de boa qualidade [9-11]. No Brasil não se observa essa tendência no setor de cerâmica vermelha, à exceção de algumas fábricas concentradas basicamente no Estado de S. Paulo, o que se reflete na produção de produtos de má qualidade na grande maioria das olarias do país.

O conhecimento de suas matérias-primas contribui diretamente para a melhora das propriedades do produto final e possibilita ao fabricante flexibilidade, redução de custos de produção e aumento no valor agregado de seu produto. Assim, o conhecimento das características das argilas não tem valor apenas acadêmico, mas também grande interesse comercial [12]. Essa preocupação com a adequada caracterização de argilas para aplicação em cerâmica vermelha e seu reflexo na produtividade e qualidade dos produtos finais se manifesta em todo o mundo [13-17], a cada dia de forma mais intensa. Assim, esse trabalho tem por objetivo a caracterização física e mineralógica de argilas utilizadas industrialmente para a produção de blocos cerâmicos, visando avaliar sua adequação a esse processo cerâmico.

\section{MATERIAIS E MÉTODOS}

Nessa pesquisa foram estudadas argilas utilizadas industrialmente para a produção de blocos cerâmicos no Estado da Paraíba. As amostras foram identificadas por A, B, C, D e E, sendo A e B oriundas da bacia hidrográfica do baixo Rio Paraíba, C da bacia hidrográfica do médio Rio Paraíba, D da bacia hidrográfica do Rio Mamanguape e E da bacia hidrográfica do Rio Taperoá. Essas bacias hidrográficas abrangem as regiões com as maiores densidades populacionais do Estado e apresentam, por conseguinte, os maiores volumes de utilização de argilas para fins cerâmicos, o que fez com que fossem as escolhidas para esse estudo.

As amostras coletadas foram secas, passadas em peneira ABNT $80(0,177 \mathrm{~mm})$ e caracterizadas por meio da determinação da distribuição de tamanho de partículas, pela técnica de espalhamento laser (Cilas 1064 LD), limites de Atterberg, conforme normalização [18, 19], análise química (via úmida), difração de raios $\mathrm{X}$ com radiação $\mathrm{CuK}_{\alpha}$ (Shimadzu, XRD 7000), análise térmica diferencial (ATD) e gravimétrica (TG), com razão de aquecimento $10{ }^{\circ} \mathrm{C} / \mathrm{min}$ (BP Engenharia, RB3000). Após caracterização, foram confeccionados corpos de prova de $100 \mathrm{~mm}$ x $20 \mathrm{~mm} \times 10 \mathrm{~mm}$ por extrusão (extrusora Vêrdez, modelo BR). Os corpos de prova foram queimados a 800,900 e $1000{ }^{\circ} \mathrm{C}$ e, em seguida, foram determinadas suas absorções de água e o módulo de ruptura à flexão pelo método dos três pontos (com velocidade de aplicação de carga de 0,5 $\mathrm{mm} / \mathrm{min}$ ). Foram determinadas também a absorção de água e a resistência a compressão simples (segundo a normalização [20]) de blocos cerâmicos industrializados produzidos com as amostras estudadas.

\section{RESULTADOS E DISCUSSÃO}

A Fig. 1 apresenta as distribuições granulométricas das amostras estudadas. As amostras apresentam largas distribuições granulométricas, com as amostras A e E apresentando as distribuições mais "grosseiras" e a amostra C a mais "fina". As amostras A e B, apesar de oriundas da mesma bacia hidrográfica, apresentam granulometria um pouco diferente, observando-se uma maior semelhança entre as distribuições das amostras A e E que são de bacias distintas.

Considera-se a fração argila de uma matéria-prima cerâmica natural a fração granulométrica com dimensão inferior a $2 \mu \mathrm{m}$ [21]; pode-se observar que a fração argila das amostras analisadas variou de $7,6 \%$ para a amostra $\mathrm{E}$ a $18,1 \%$ para a amostra $\mathrm{C}$. As amostras apresentam fração argila abaixo do mínimo indicado pelo diagrama de Winkler $[22,23]$ para massas cerâmicas visando a produção de blocos (tijolos furados) (fração argila entre 20 e 30\%). Uma massa cerâmica por não poder ser constituída apenas por argila (em virtude de dificuldade que surgiriam no processamento) é formulada contendo materiais não plásticos, o que acarreta uma "mistura" de granulometrias, sendo a fração mais "fina" associada à argila e as demais ("mais grosseira") relacionadas aos materiais friáveis. O diagrama de Winkler auxilia no estudo da composição granulométrica ótima, indicando a dosagem de partículas finas, médias e grossas, que possibilitariam obter as melhores propriedades no produto final. No entanto, trabalhos analisando a viabilidade de utilização de argilas em cerâmica vermelha, indicaram argilas, cujas composições também não se encaixavam na região do diagrama de Winkler, como adequadas para a produção de blocos cerâmicos [11,24].

Os limites de Atterberg das amostras estão na Tabela I. Os limites de liquidez (LL) e de plasticidade (LP) variaram de 34,8 a $40 \%$, e de 17,8 a $20,5 \%$, respectivamente, enquanto

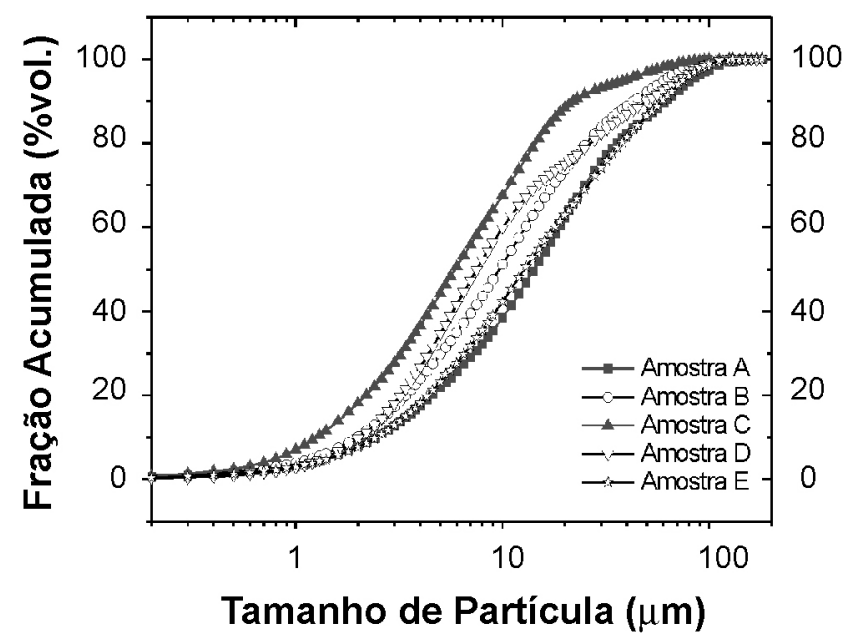

Figura 1: Distribuição granulométrica das amostras. [Figure 1: Particle size distribution of the samples.] 
Tabela I - Limites de Atterberg das amostras.

[Table I - Atterberg limits of the samples.]

\begin{tabular}{cccc}
\hline Amostras & $\begin{array}{c}\text { Limite de } \\
\text { Liquidez } \\
(\%)\end{array}$ & $\begin{array}{c}\text { Limite de } \\
\text { Plasticidade } \\
(\%)\end{array}$ & $\begin{array}{c}\text { Índice de } \\
\text { Plasticidade } \\
(\%)\end{array}$ \\
\hline A & 38,5 & 20,5 & 18,0 \\
B & 40,0 & 19,0 & 21,0 \\
C & 37,5 & 19,8 & 17,7 \\
D & 38,9 & 18,8 & 20,1 \\
E & 34,8 & 17,8 & 17,0 \\
\hline
\end{tabular}

o índice de plasticidade situou-se entre 17,0 e $21,0 \%$. Com base em dados da literatura $[5,21,25,26]$ verifica-se que os valores obtidos estão dentro dos intervalos observados para cerâmica vermelha, 30 a $60 \%$ para o LL, 15 a 30\% para o LP e 10 a $30 \%$ para o IP. Com base no limite de plasticidade verifica-se que as plasticidades das argilas são semelhantes, sendo E a menos plástica e A a mais plástica. Essas argilas apresentam distribuições granulométricas muito parecidas, assim a diferença de plasticidade deve está provavelmente associada a alguma diferença mineralógica ou no teor de matéria orgânica.

A Tabela II apresenta a composição química das amostras analisadas. Observa-se uma composição típica de argila para cerâmica vermelha [21], com predominância de $\mathrm{SiO}_{2} \mathrm{e} \mathrm{Al}_{2} \mathrm{O}_{3}$ e altos teores de $\mathrm{Fe}_{2} \mathrm{O}_{3}$.

Os padrões de difração de raios $\mathrm{X}$ das amostras analisadas estão na Fig. 2. As amostras apresentam basicamente as seguintes fases cristalinas: quartzo, caulinita, mica/ilita, feldspatos (sódico e potássico). As amostras A, B e C também contêm um hidróxido sílico-aluminoso $\left(\mathrm{NaCa}_{2}\left(\mathrm{Fe}^{2+}{ }_{4} \mathrm{Al}\right) \mathrm{Si}_{6} \mathrm{Al}_{2} \mathrm{O}_{22}(\mathrm{OH})_{2}\right)$ ("ferropargasite") e as amostras $\mathrm{B}$ e $\mathrm{C}$ apresentam goetita (hidróxido de ferro). Com base nos padrões de difração e nas composições químicas (Tabela II) observa-se que as amostras apresentam caulinita mal cristalizada, porque a intensidade do pico de difração é pequena, mas sua presença significativa nas amostras é inferida a partir do elevado teor de óxido de alumínio presente na composição química e da não existência de fases fontes de óxido de alumínio em grande quantidade (como gibsita ou boemita) (Fig. 2).

Mesmo as argilas oriundas da mesma bacia hidrográfica apresentam constituição um pouco diferente, o que evidencia o caráter particular de cada amostra quando se trata de jazimentos de cerâmica vermelha.

Na Fig. 2 pode-se inferir que a pequena fração argila observada na Fig. 1 pode estar associada à presença de partículas de mica, cuja anisometria pode ter induzido o equipamento de análise a classificá-las como partículas maiores, e a presença dos feldspatos, que apresentam partículas com dimensões superiores a $2 \mu \mathrm{m}$. A presença

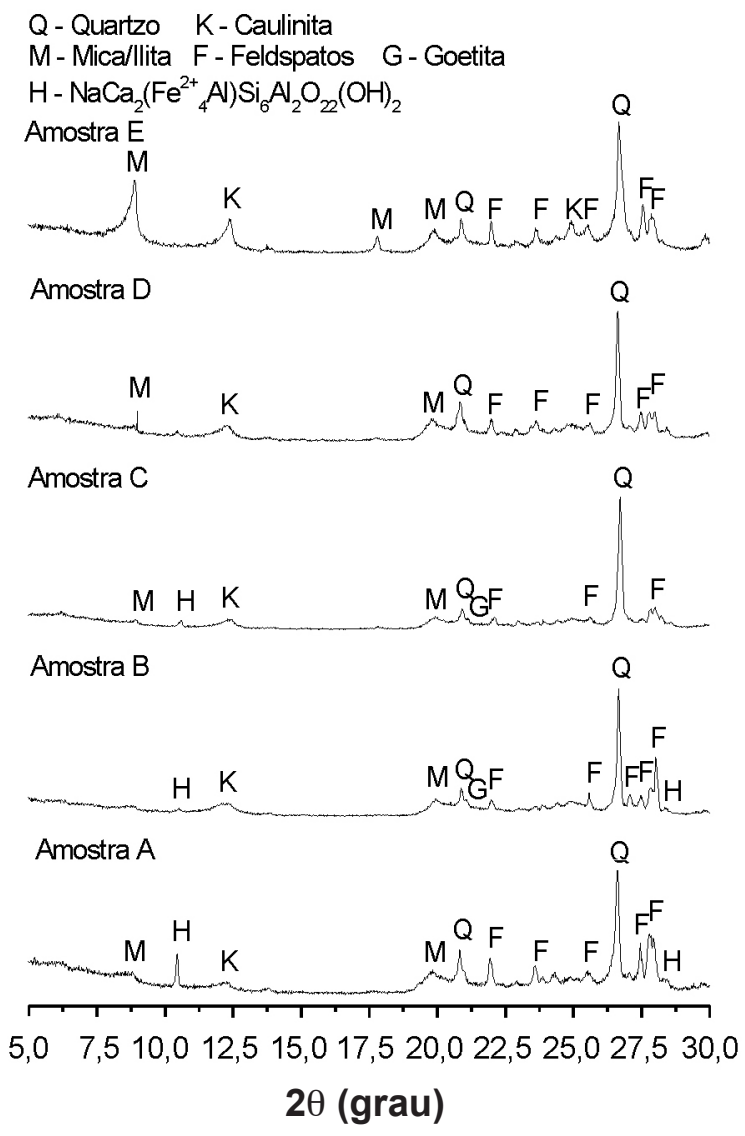

Figura 2: Padrão de difração de raios X das amostras. [Figure 2: X-Ray diffraction patterns of the samples.]

Tabela II - Composição química das amostras.

[Table II - Chemical composition of the samples.]

\begin{tabular}{ccccccccc}
\hline \multirow{2}{*}{ Amostras } & \multicolumn{7}{c}{ Porcentagem (em massa) } \\
\cline { 2 - 8 } & $\mathrm{PF}$ & $\mathrm{SiO}_{2}$ & $\mathrm{Al}_{2} \mathrm{O}_{3}$ & $\mathrm{Fe}_{2} \mathrm{O}_{3}$ & $\mathrm{CaO}$ & $\mathrm{MgO}$ & $\mathrm{Na}_{2} \mathrm{O}$ & $\mathrm{K}_{2} \mathrm{O}$ \\
$\mathrm{A}$ & 9,68 & 56,53 & 22,74 & 7,44 & 0,23 & 0,99 & 0,95 & 1,35 \\
$\mathrm{~B}$ & 10,37 & 56,19 & 24,52 & 6,50 & 0,12 & 0,64 & 0,65 & 0,91 \\
$\mathrm{C}$ & 9,67 & 49,37 & 30,80 & 6,85 & 0,16 & 0,70 & 1,00 & 1,37 \\
$\mathrm{D}$ & 8,61 & 57,35 & 25,33 & 5,80 & 0,13 & 0,77 & 0,83 & 1,08 \\
$\mathrm{E}$ & 10,92 & 53,63 & 24,61 & 7,57 & 0,11 & 0,81 & 0,76 & 1,52 \\
\hline
\end{tabular}

PF: Perda ao Fogo 
de feldspatos e mica/ilita é a razão da presença de óxido de sódio e potássio em certa quantidade nas amostras estudadas, não sendo o potássio oriundo apenas dos argilominerais. A presença de felsdpatos, mica/ilita e quartzo provavelmente influencia muito o comportamento de plasticidade das amostras analisadas. O feldspato e o quartzo agem como redutores de plasticidade, sendo possivelmente um dos motivos para se ter massas com limites de plasticidade adequados para cerâmica vermelha (valores medianos), sem a necessidade de adição de materiais friáveis. Caso as amostras apresentassem altos teores de argilominerais (fração argila), provavelmente teriam alta plasticidade e seriam inadequadas (ou comprometeria em muito) ao processamento por extrusão.

Com base nos dados obtidos por difração de raios X, verifica-se que as amostras $\mathrm{A}$ e $\mathrm{E}$ apresentam composições mineralógicas semelhantes; no entanto, a $\mathrm{E}$ apresenta possivelmente maior teor de mica/ilita. Por outro lado, estudos mostraram que os valores de limites de plasticidade dos argilominerais decrescem na seguinte ordem: montmorilonita, ilita, caulinita mal cristalizada e caulinita bem cristalizada [27-29]. Assim, esperar-se-ia com base nos resultados granulométricos e mineralógicos que a amostra E apresentasse uma maior plasticidade, o que não ocorre. Então, acredita-se que a maior plasticidade da amostra A está associada ao seu teor de matéria orgânica.

A Fig. 3 apresenta as curvas de ATD e TG das amostras estudadas. De forma geral as amostras apresentam: picos endotérmicos entre 120 e $140{ }^{\circ} \mathrm{C}$, possivelmente relacionados à eliminação da água livre presente nas amostras; picos endotérmicos entre 545 e $575^{\circ} \mathrm{C}$ associados provavelmente à dexidroxilação dos argilominerais presentes nas argilas e picos exotérmicos entre 860 e $925{ }^{\circ} \mathrm{C}$ possivelmente relacionados à formação de espinélio após a total destruição da estrutura da mica/ilita [30, 31]. Entretanto, esse pico em algumas micas/ilitas pode não ser bem pronunciado ou ocorrer em temperatura acima de $1000{ }^{\circ} \mathrm{C}$ [30]. Acredita-se que o pico exotérmico observado não esteja relacionado à nucleação da mulita após destruição da estrutura da caulinita, porque esse pico ocorre em temperaturas próximas de $975{ }^{\circ} \mathrm{C}$ [21].

Por meio das análises térmicas verifica-se também que as amostras A, D e E apresentam bandas exotérmicas entre 130 e $500{ }^{\circ} \mathrm{C}$ (mais pronunciada na amostra $\mathrm{A}$ ), que estão possivelmente relacionadas à queima da matéria orgânica. Verifica-se também um pequeno pico endotérmico na amostra $\mathrm{B}$ em torno de $320^{\circ} \mathrm{C}$; todavia ainda não há um entendimento da origem desse pico. Poderia estar relacionado à dexidroxilação de gibsita; entretanto, não se observou a presença de gibsita nos difratogramas e a história geológica desse tipo de jazimento não viria ao encontro de presença de gibsita. Analisando as curvas da análise termogravimétrica observa-se que ocorreu uma perda de massa próxima em todas as amostras, variando de 10,5 a 12,5\%, o que vem ao encontro dos dados de perda ao fogo obtidos com a análise química. No entanto, a amostra A apresentou uma perda de massa mais acentuada que as outras amostras entre $140 \mathrm{e}$ $500{ }^{\circ} \mathrm{C}$, o que, provavelmente, está associada à queima de
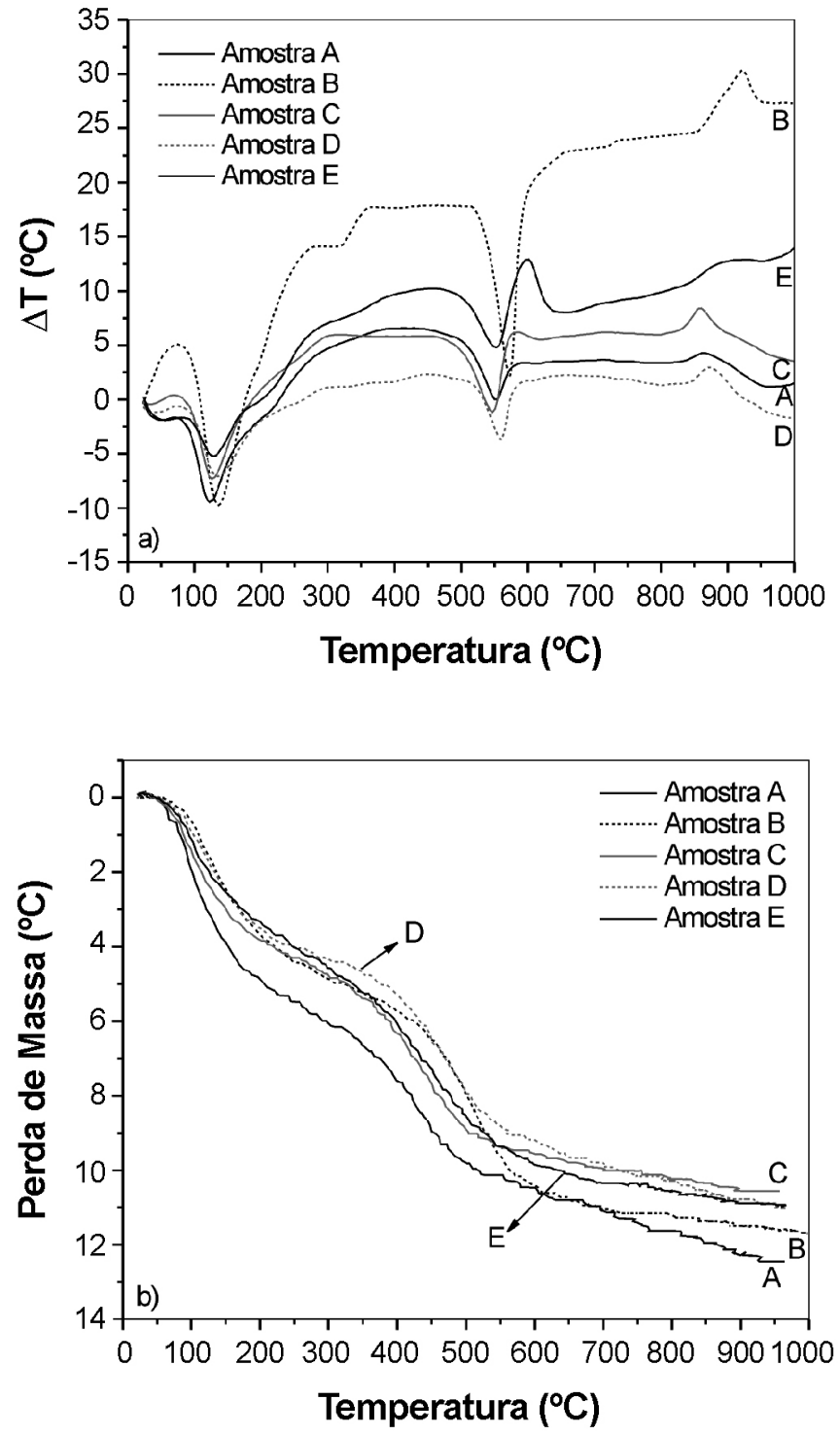

Figura 3: Curvas de análise térmica diferencial (a) e gravimétrica (b) das amostras.

[Figure 3: Differential thermal analysis (a) and thermogravimetric analysis curves of the samples.]

matéria orgânica e indica que a amostra apresenta um teor de matéria orgânica superior ao das demais amostras. Com base nesses resultados mesmo as argilas oriundas da mesma bacia hidrográfica apresentam teores de matéria orgânica distintos, o que vai influenciar na sua plasticidade (tal como observado na Tabela I). O motivo da diferença de plasticidade entre as amostras A e E, apesar de suas distribuições granulométricas tão semelhantes e composição mineralógica similar, está provavelmente associado ao teor de matéria orgânica. Por meio da caracterização realizada podem-se inferir algumas características dos blocos que seriam produzidos utilizando-se essas argilas e se elas seriam adequadas para a produção de blocos cerâmicos. A amostra E, pela pequena fração argila (argila com menor fração argila) e alto teor de mica, provavelmente terá os corpos de prova com maior absorção de água e menor módulo de ruptura 
com a queima em baixas temperaturas, da ordem de 800 e $900{ }^{\circ} \mathrm{C}$; entretanto, com a queima a $1000^{\circ} \mathrm{C}$ provavelmente a resistência melhorará com a nucleação e crescimento de fases cristalinas que confeririam maior resistência. A amostra A, apesar de apresentar granulometria grosseira, possui plasticidade mais elevada que a amostra E (não excessiva) (Tabela I), o que possibilitará, possivelmente, a produção de peças com menor quantidade de defeitos oriundos da etapa de conformação (uma microestrutura mais homogênea) e favorecerá a obtenção de corpos de prova com menor absorção de água e, por conseguinte, maior resistência mecânica que os da amostra $\mathrm{E}$ após queima em baixas temperaturas $\left(800-900^{\circ} \mathrm{C}\right)$. Por outro lado, a amostra $\mathrm{C}$ apresenta a granulometria mais fina (maior fração argila), baixo teor de micas e plasticidade adequada ao processo de extrusão; assim, será, provavelmente, a que apresentará menor absorção de água e maior módulo, particularmente em baixas temperaturas de queima. Assim, de forma geral, com base na caracterização mineralógica realizada e no conhecimento dos ciclos de queima praticados pelas olarias do Estado da Paraíba (temperaturas de queima entre 800 e $900{ }^{\circ} \mathrm{C}$, heterogeneidades dentro do forno e queima muito rápida), observa-se que provavelmente todas as amostras, à exceção da amostra $\mathrm{E}$, poderiam ser utilizadas para a produção de blocos cerâmicos.

A Fig. 4 apresenta a absorção de água e o módulo de ruptura à flexão dos corpos de prova produzidos por extrusão após queima a 800,900 e $1000{ }^{\circ} \mathrm{C}$. Os corpos de prova da amostra $\mathrm{E}$ apresentam maior absorção de água em todas as temperaturas. Os corpos de prova das amostras A e D apresentam a menor absorção após queima a 800 e 900 ${ }^{\circ} \mathrm{C}$; no entanto, após $1000{ }^{\circ} \mathrm{C}$ praticamente todas as amostras apresentaram a mesma absorção de água (considerando o desvio padrão). Segundo dados da literatura [32], que indicam absorção de água inferior a $25 \%$ para os corpos de prova de argilas para produção de blocos cerâmicos, verifica-se que todas as amostras apresentaram valores de acordo com o indicado.

Verifica-se que a amostra $\mathrm{C}$ apresenta os maiores módulos de ruptura em todas as temperaturas de queima. As amostras E e B são as que apresentam os menores valores do módulo de ruptura após queima a 800 e $900{ }^{\circ} \mathrm{C}$; entretanto, após queima a $1000{ }^{\circ} \mathrm{C}$ os corpos de prova das amostras A, B, D e E possuem basicamente o mesmo módulo de ruptura (considerando o desvio padrão). Comparando os resultados obtidos com os da literatura [32] para os valores dos módulos de ruptura dos corpos de prova de argilas para a produção de blocos cerâmicos (superior a 5,5 MPa), verificase que todas as amostras apresentam valores superiores aos indicados. Observa-se também, que os resultados obtidos são semelhantes aos apresentados em outros estudos [11, 24, 26] abordando a caracterização de argilas para cerâmica vermelha. De forma geral, todas as suposições levantadas com base nos resultados da caracterização mineralógica se concretizaram, evidenciando a importância da adequada caracterização das matérias-primas.

A Tabela III apresenta os valores de absorção de água
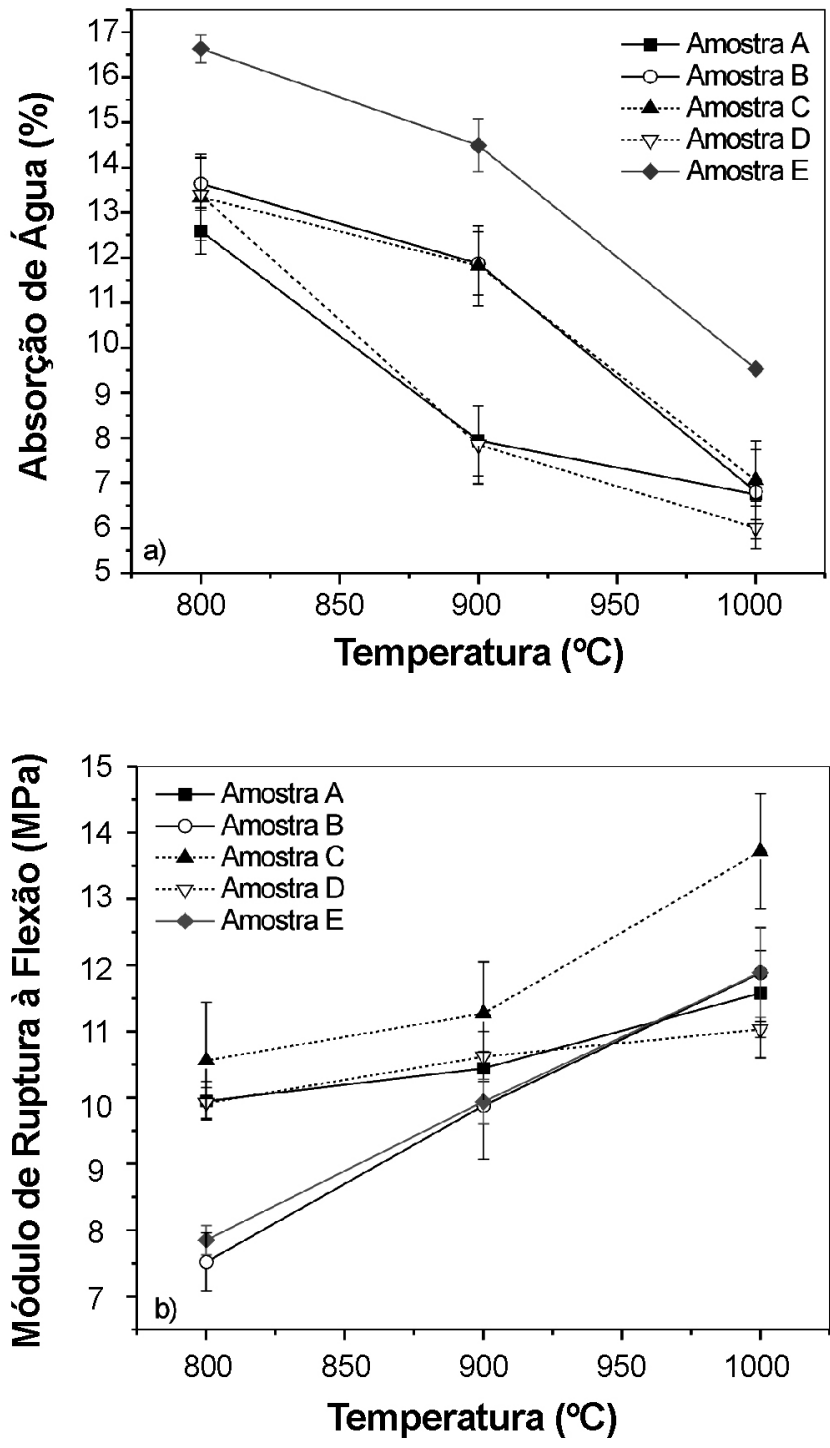

Figura 4: Absorção de água (a) e módulo de ruptura à flexão (b) dos corpos de prova após queima.

[Figure 4: Water absorption (a) and modulus of rupture (b) of the fired test specimens.]

e resistência à compressão simples dos blocos cerâmicos produzidos com as amostras estudadas e queimados em olarias do Estado da Paraíba. Os blocos da amostra E foram os que apresentam a maior absorção e a menor resistência à compressão simples, enquanto os blocos da amostra $\mathrm{C}$ apresentam a maior resistência. É interessante mencionar também o comportamento dos blocos da amostra A, que apresentam a menor absorção de água e uma das maiores resistências mecânicas, o que provavelmente está associado, não apenas a sua composição mineralógica, mas também a matéria orgânica, que favorece a plasticidade da massa e por conseguinte uma série de benefícios durante o processo de conformação. Comparando os resultados da Tabela III com os valores indicados na normalização [33] para blocos cerâmicos de vedação (absorção entre 8 e $22 \%$ e resistência superior a 1,5 MPa), verifica-se que todas os blocos atendem as especificações, à exceção dos blocos da amostra E. 
Tabela III - Absorção de água e resistência à compressão simples dos blocos cerâmicos industrializados.

[Table III - Water absorption and simple compression strength of the commercial ceramic bricks.]

\begin{tabular}{ccc}
\hline Amostras & $\begin{array}{c}\text { Absorção de } \\
\text { água (\%) }\end{array}$ & $\begin{array}{c}\text { Resistência à } \\
\text { compressão } \\
\text { simples (MPa) }\end{array}$ \\
\hline A & $8,97 \pm 0,18$ & $1,96 \pm 0,52$ \\
B & $9,21 \pm 0,80$ & $1,96 \pm 0,27$ \\
C & $10,57 \pm 0,95$ & $2,26 \pm 0,58$ \\
D & $9,51 \pm 0,14$ & $1,67 \pm 0,48$ \\
E & $12,65 \pm 0,14$ & $0,52 \pm 0,20$ \\
\hline
\end{tabular}

Os resultados evidenciam a grande importância dos ensaios de caracterização na seleção das matérias-primas adequadas para a produção de blocos cerâmicos, permitindo estimar o comportamento das peças a serem produzidas a partir do adequado conhecimento dos jazimentos. Indicam também que se deve ter cautela ao indicar ou não uma matériaprima como adequada para produção de blocos ou telhas, sem conhecer o ciclo de queima a ser utilizado na olaria, já que a comparação com indicações da literatura não leva em consideração que as características de processamento na empresa e no laboratório podem ser distintas. O que ressalta ainda mais a importância da caracterização das matériasprimas para o total entendimento do comportamento de queima e evolução microestrutural da peça produzida.

\section{CONCLUSÕES}

As amostras possuem granulometria com baixo teor de fração argila, mas apresentam limites de Atterberg dentro do intervalo indicado para utilização em cerâmica vermelha; são constituídas basicamente por quartzo, caulinita, feldspatos e mica/ilita, com algumas amostras apresentando também goetita e hidróxido sílico-aluminoso; apresentam absorção de água e módulo de ruptura à flexão, obtidos em ensaios de laboratório, dentro da faixa de valores indicada na literatura para argilas usadas na produção de blocos cerâmicos.

Os ensaios de caracterização permitiram prever, com base nos conhecimentos dos ciclos de queima, a adequação ou não das matérias-primas para a produção de blocos cerâmicos.

\section{AGRADECIMENTOS}

À FAPESQ/MCT/CNPq (001/06) pelo apoio financeiro.

\section{REFERÊNCIAS}

[1] A. L. D. Gesicki, P. C. Boggiani, A. R. Salvatti, Cerâmica Industrial 7 (2002) 44.

[2] I. M. G. Santos, J. M. Silva, M. F. S. Trindade, L. E. B. Soledade, A. G. Souza, C. A. Paskocimas, E. Longo,
Cerâmica 51 (2005) 144.

[3] R. R. Menezes, G. A. Neves, H. C. Ferreira, Cerâmica 47 (2001) 77.

[4] R. S. Macedo, A. G. S. Galdino, C. R. S. Morais, H. C. Ferreira, Cerâmica 41 (1996) 259.

[5] R. S. Macedo, Estudo das matérias-primas e tijolos furados produzidos no Estado da Paraíba, Diss. Mestrado, DEQ-CCT-UFPB (1997) 107.

[6] R. R. Menezes, H. S. Ferreira, G. de A. Neves, H. C. Ferreira, Cerâmica 49 (2003) 120.

[7] D. M. Morais, R. M. Sposto, Ceram. Ind. 11 (2006) 35.

[8] R. P. S. Dutra, M. L. Varela, R. M. Nascimento, U. U. Gomes, C. A. Paskocimas, P. T. Melo, Ceram. Ind. 11 (2006) 42.

[9] W. H. Fitzjohn, W. E. Worall, Trans. Brit. Ceram. Soc. 79 (1990) 74.

[10] H. M. Shah, R. M. Savsami, T. K. Dan, Tile \& Brick Int. 8 (1992) 328.

[11] G. P. Souza, R. Sanchez, J. N. F. Holanda, Cerâmica 48 (2002) 102.

[12] G. P. Souza, S. J. G. Sousa, L. A. H. Terrones, J. N. F. Holanda, Cerâmica 51 (2005) 381.

[13] M. Dondi, Appl. Clay Sci. 15 (1999) 337.

[14] M. Hajjaji, S. Kacim, A. Alami, A. El Bouadili, M. El Mountassir, Appl. Clay Sci. 20 (2001) 1.

[15] G. Bianchini, R. Laviano, S. Lovo, C. Vaccaro, Appl. Clay Sci. 21 (2002) 165.

[16] M. Hajjaji, S. Kacim, M. Boulmane, Appl. Clay Sci. 21 (2002) 203.

[17] J. Sei, A. A. Touré, J. Olivier-Fourcade, H. Quiquampoix, S. Staunton, J. C. Jumas, M. Womes, App. Clay Sci. 27 (2004) 235.

[18] Associação Brasileira de Normas Técnicas, NBR 6459, "Determinação do limite de liquidez - método de ensaio", Rio de Janeiro, RJ (1984).

[19] Associação Brasileira e Normas Técnicas, NBR 7180, "Determinação do limite de plasticidade - método de ensaio", Rio de Janeiro, RJ (1984).

[20] Associação Brasileira e Normas Técnicas, NBR 152703, "Componentes cerâmicos - Parte 3: Blocos cerâmicos para alvenaria estrutural e de vedação - Métodos de ensaio", Rio de Janeiro, RJ (2005).

[21] P. Souza Santos, Ciência e Tecnologia de Argilas, $3^{\text {a }}$ Ed., Vol. 1, Edgard Blücher, S. Paulo, SP (1992) 4.

[22] S. F. Pracidelli, F. G. Melchiades, Cerâmica Industrial 2 (1997) 31.

[23] M. Dondi, B. Fabbri, G. Guarini, Clay Minerals 33 (1998) 435.

[24] C. M. F. Vieira, T. M. Soares, S. N. Monteiro, Cerâmica 49 (2003) 245.

[25] L. F. A. Campos, R. S. de Macedo, P. K. Kiyohara, H. C. Ferreira, Cerâmica 45 (1999) 295.

[26] C. M. F. Vieira, J. N. F. Holanda, D. G. Pinatti, Cerâmica $46(2000) 14$.

[27] R. E. Grim, Clay mineralogy, $2^{\text {nd }}$ Ed., McGraw-Hill Book, New York, EUA (1968).

[28] J. Rawet, P. Souza Santos, Cerâmica 26 (1980) 198. 
[29] L. C. S. Silveira, "Plasticidade de solos lateríticos: métodos de ensaios e efeito da temperatura de secagem". Diss. Mestrado, DEC-CCT/UFPB (1984) 110.

[30] R. E. Grim, R. A. Rowland, Differential thermal analysis of clay minerals and other hydrous materials. Part 1. Disponível em www.minsocam.org/ammin/AM27/ AM27_746.pdf. Acesso em 07/11/2007.
[31] J. H. de Araújo, N. F. da Silva, W. Acchar, U. U. Gomes, Mater. Res. 7 (2004) 359.

[32] I. L. Barzaghi, A. Salge, Cerâmica 28 (1982) 15.

[33] Associação Brasileira e Normas Técnicas, NBR 15270-

1, "Componentes cerâmicos - Parte 1: Blocos cerâmicos para alvenaria de vedação - Terminologia e requisitos", Rio de Janeiro, RJ (2005).

(Rec. 20/11/2007, Rev. 01/05/2008, Ac. 30/05/2008) 